\title{
Non-specific diagnosis of bacterial pneumonia in children
}

\author{
Matti Korppi
}

Received: 29 June 2009 / Accepted: 15 September 2010 / Published online: 28 September 2010

(C) Springer-Verlag 2010

To the Editor:

From the late 1990s onwards, antigen, antibody, and immune complex assays have been applied to the diagnosis of pneumococcal pneumonia. The findings have shown a poor correlation with non-specific inflammatory markers like procalcitonin (PCT), and no combination of PCT, C-reactive protein (CRP), and white blood cells (WBC) has been able to screen bacterial from viral pneumonia [1]. Schützle et al. published in the journal a pragmatic retrospective analysis on PCT in 327 children with lower respiratory infection (ARI) to clarify if PCT could distinguish bacterial cases requiring antibiotics from viral ARI [1]. Viruses and atypical bacteria were studied by polymerase chain reaction in nasopharyngeal aspirates. However, no methods were available for pneumococci. PCT was $<0.1 \mathrm{ng} / \mathrm{ml}$ in 132(40.3\%) cases, and 94(71\%) of them were successfully treated without antibiotics.

Thirty-eight patients with PCT $<0.1 \mathrm{ng} / \mathrm{ml}$ received antibiotics, and were analyzed further [2]. After exclusions, only 12 children (four viral, four atypical bacterial, and four unknown infections) were checked, and none of them had any findings suggestive for typical bacterial infection [1]. The authors concluded that PCT $<0.1 \mathrm{ng} / \mathrm{ml}$ identified children with ARI in whom antibiotics can be withheld [2]. However, the critical patients for any conclusions are these
26/132(19.7\%) ARI cases with low PCT, treated with antibiotics and excluded from the analyses.

Due to increasing antibiotic resistance, antibiotic use for children's respiratory infections should be lessened in the community. WBC (especially neutrophils) rise more rapidly than PCT and CRP in invasive bacterial infections, being helpful for diagnosing pneumococcal bacteremia in young children [3]. Thus, the combined use of the markers sounds rationale in children with pneumonia. Rapid, sufficiently reliable bedside tests are currently available for PCT, CRP, and $\mathrm{WBC}$, and their combined use should be studied in children with pneumonia. Children with other respiratory infections rarely benefit from any laboratory tests.

\section{References}

1. Korppi M (2004) Non-specific host response markers in the differentiation between pneumococcal and viral pneumonia: what is the most accurate combination? Pediatr Int 46:545-550

2. Schützle H, Forster J, Superti-Furga A, Berner R (2009) Is serum procalcitonin a reliable diagnostic marker in children with acute respiratory tract infections? A retrospective analysis. Eur J Pediatr 168:1117-1124. doi:10.1007/s00431-008-0899-3

3. Sur DK, Bukont EL (2007) Evaluating fever of unidentifiable source in young children. Am Fam Phys 75:1805-1811
M. Korppi $(\bowtie)$

Pediatric Research Center,

Tampere University and University Hospital,

33014 Tampere, Finland

e-mail: matti.korppi@uta.fi 